\title{
The role of questions in the science classroom - how girls and boys respond to teachers' questions
}

\author{
Nina Eliasson, Karl Göran Karlsson \& Helene Sørensen
}

To cite this article: Nina Eliasson, Karl Göran Karlsson \& Helene Sørensen (2017) The role of questions in the science classroom - how girls and boys respond to teachers' questions, International Journal of Science Education, 39:4, 433-452, DOI: 10.1080/09500693.2017.1289420

To link to this article: https://doi.org/10.1080/09500693.2017.1289420

\section{Published online: 01 Mar 2017.}

Submit your article to this journal ๘

Џll Article views: 2532

Q View related articles $\smile$

View Crossmark data $₫$

它

Citing articles: 4 View citing articles $ऍ$ 


\title{
The role of questions in the science classroom - how girls and boys respond to teachers' questions*
}

\author{
Nina Eliasson ${ }^{a}$, Karl Göran Karlsson ${ }^{a}$ and Helene Sørensen ${ }^{b}$ \\ ${ }^{a}$ DMA, Mid Sweden University, Härnösand, Sweden; ${ }^{b}$ DPU, Aarhus University, København NV, Denmark
}

\begin{abstract}
The purpose of this study was to explore (a) to what extent male and female science teachers pose different types of questions and (b) if the type of science question posed influences the extent to which boys or girls respond to them. Transcripts of the teacher-student interaction in a whole-class situation were analysed, with attention paid to interactions that involved science questions. Closed and open questions were used. Results revealed that the percentage of closed questions posed corresponded to $87 \%$. Results show that teachers mainly use closed questions, and responses from boys to closed questions are in the majority regardless of if the question is posed by a female teacher $(56 \%)$ or a male teacher (64\%). Both categories of closed questions are mainly considered lower order questions that do not facilitate higher cognitive levels in students. Thus, a direct consequence of an excessive use of this type of questions may be that both boys and girls will be given less opportunities to practise their ability to talk about science. Less access to general classroom interaction may also affect girls' attitudes to science in a negative way which could ultimately hamper the recruitment of girls to higher scientific studies.
\end{abstract}

\section{ARTICLE HISTORY}

Received 17 June 2016

Accepted 28 January 2017

\section{KEYWORDS}

Science education; gender; open or closed question

\section{Introduction}

In order to create equal opportunities for learning, it is important to include all students in interaction since ample research has described the importance of communication for science learning (Lemke, 1990; Mortimer \& Scott, 2003; Wertsch, 1991). Communication covers a broad variety of modes also in a classroom setting. More specifically, it can be about how teachers put questions, and to whom, and who responds to questions posed and how the answers are given. Both older and more recent studies have highlighted how different types of science questions influence students' knowledge acquisition (e.g. Blosser, 2000; Chin, 2006; Duschl \& Osborne, 2002; Jensen, McDaniel, Woodard, \& Kummer, 2014; Newton, Driver, \& Osborne, 1999; Wilen, 1991; Yip, 2004) and it is also shown that the majority of questions are at the factual knowledge level (Blosser, 2000; Lord \& Baviskar, 2007). This is the scope of this paper with particular focus on gender.

CONTACT Nina Eliasson nina.eliasson@miun.se E DMA, Mid Sweden University, Universitetsbacken 1, Härnösand, Sweden

* Research conducted at Mid Sweden University, Department of Science Education and Mathematics.

(c) 2017 Informa UK Limited, trading as Taylor \& Francis Group 
To what degree does the type of science question that male and female teachers pose in science classrooms influence how boys and girls participate in teacher-student interactions? This question is important since a recent study of Swedish science lessons at the end of lower secondary school confirms previous research describing how boys tend to dominate classroom interaction compared to girls (Eliasson, Karlsson, \& Sørensen, 2016). Another finding was that both male and female teachers still interact more often with boys than with girls. These findings are in agreement with previous research and, over the years, only minor changes with respect to gendered share in teacher-student interaction is reported.

Swedish girls today have higher average grades than boys in all school subjects except in Physical Education and Health (Skolverket, 2009). Girls also performed better in science than boys in the last Programme for International Student Assessment (PISA) (Organisation for Economic Co-operation and Development [OECD], 2014). One reasonable explanation may be that girls' academic success cannot to any great extent be negatively affected by their limited access to classroom interaction. Moreover, there may be other differences in the general science-classroom communication, and as early as 1998, Kelly (1988) argued that it was important to know where the inequalities were manifest. One way to identify the gendered inequalities in classroom interaction is to study the quality of the communication by identifying different types of questions posed in the science classrooms, who is posing these questions and who is answering them.

In summary, we know that a majority of the questions posed in science class are to be responded to by the recall of factual knowledge. We also know that boys dominate the classroom interaction as compared to girls. But we do not know to what degree boys or girls choose to respond to the different types of science questions posed. Finding this out is of great interest since with this information available, it is possible to draw conclusions about potential quality differences between boys' and girls' communication with their teachers.

In this study, science questions have been classified according to their cognitive level. We have applied a gender perspective to this issue by examining the extent to which boys or girls respond to different types of questions. Additionally, we extend this gender perspective to find out if teachers' gender affects the degree to which boys or girls respond to different questions.

In the background, we dwell on the importance of language in a science teaching context. The question classification system and its application together with previous research on gendered issues in a school science context is also addressed.

\section{Background}

The Swedish curriculum for the compulsory school includes the core content that should be covered in the teaching, together with knowledge requirements defining acceptable knowledge and different grades. The importance of different forms of scientific communication is clearly stated. It is also clear that one important teaching purpose expressed in the syllabi is that of strengthening students' ability to use scientific language. Included in the Swedish Curriculum, the syllabi in Biology, Chemistry and 
Physics all have the same introductory text describing the aims for teaching the science subjects. We can read that:

- Teaching should give pupils opportunities to use and develop knowledge and tools for expressing their own arguments and examining those of others in contexts where knowledge of biology (or chemistry or physics) is of importance.

- Teaching should contribute to pupils developing familiarity with the concepts, models and theories of biology (or chemistry or physics), as well as an understanding of how they are shaped in interaction with experiences from studies of the surrounding world. In addition, teaching should contribute to pupils developing the ability to discuss, interpret and produce texts and various forms of aesthetic expressions with scientific content (National Agency for Education, 2011, pp. 105, 120, 134).

The authors define science as being socially constructed as described in previous research (Driver, Newton, \& Osborne, 2000). This entails that in order to learn science, students need to participate actively, through talking and writing, in thinking through and making sense of the different scientific events to which they are being introduced (Driver, Asoko, Leach, Mortimer, \& Scott, 1994). Students' active involvement in the ongoing communication during science lessons is important since the act of talking itself is considered to be central to the meaning-making process and is thereby central to science learning (Mortimer \& Scott, 2003). It is widely held that science learning involves learning to 'talk science', and Lemke (1990) means that this practice of talking science takes place in classroom discourse. A sociolinguistic perspective on learning within a discipline implies that students need to adopt the norms of the language of that discipline (Newton et al., 1999).

Being, or not being involved, in ongoing science communication may lead to differences in the conditions for the acquisition of knowledge. Participation in ongoing communication may also affect attitudes towards school science, and in the long run affect who will aim for a future career in science, technology, engineering or mathematics. There are indications that interaction and communication between teachers and students have a generally positive effect on students' motivation and if the students are engaged in science education (Moeller Andersen \& Lund Nielsen, 2013). In a review of the literature on attitudes towards science Osborne, Simon, and Collins (2003) describe gender and the quality of teaching as being of the most crucial importance in shaping attitudes towards science.

\section{To promote the use of scientific language}

The teacher, not the student, continues to be at the centre of educational practices and is the person that often initiates most of the discourse in the classroom most of the time (Duschl \& Osborne, 2002). Research has shown that learning is particularly effective if students contribute to classroom talk (Jurik, Gröschner, \& Seidel, 2013). Osborne et al. (2003) argue that 'It is not enough for students to hear explanations from experts (e.g. teachers, books, films and computers), they also need to practice using the ideas for themselves' (p. 556). They assert that when students practise posing and answering scientific questions, they become active participants in the 'community of science'. Science education 
is about giving students opportunities to engage in activities that require them to reason and use the language of science with peers and teachers, and to engage in the construction and evaluation of scientific argument together (Duschl \& Osborne, 2002). Moreover, reasoning and the justification process provides a foundation for the effective communication of scientific ideas (Chapin \& Anderson, 2003; Chin, 2007). It has been shown that a heavy reliance on lower order questioning strategies is correlated with an activation of lower cognitive levels in students, and that these questioning practices are also related to students' involvement with science concepts (Smart \& Marshall, 2013). It has also been shown that in classrooms where higher order questioning was observed, students also had a deeper understanding of science concepts, formulated hypotheses and used evidence to draw conclusions about phenomena (Smart \& Marshall, 2013). Blosser (2000) argues that it is important to help students to develop the skills of acquiring and processing data into useful information, and not simply to train them to memorise information, and recall it. According to Blosser, this can be achieved by varying the types of questions posed, since it is believed that different types of teacher-initiated questions influence different levels of thinking operations in students. Likewise, Smart and Marshall (2013) suggest that teachers can facilitate higher cognitive levels in their students through the questions they choose to pose, and that 'One way in which teachers can begin to increase the quality of their questioning is to plan specific questions in advance of their instruction' (p. 256).

\section{Different types of questions}

In the past, research has proposed several ways to classify cognitive questions, and regardless of the differences in complexity of these classification systems, most are based on Bloom's Taxonomy of Educational Objectives (Blosser, 2000). Bloom and his team of theorists developed a series of six learning levels for categorising the degree of abstraction of questions (Bloom, 1956). The main distinction in types of question is between questions that it is possible to answer by recalling of factual knowledge, or those that are supposed to require some kind of higher order thinking skills.

On the lowest level, according to Bloom's taxonomy defined as the knowledge level, students are supposed to remember, or retrieve previously learnt material. At this level, students are typically asked to describe, list or name the factual information they have learnt in class (Lord \& Baviskar, 2007). These questions are also known as lower order questions (Yip, 2004). An emphasis on lower order, or recall questions encourages students to memorise information (Chin, 2004) and in many classrooms, these questions are extensively used by teachers to evaluate the students' factual knowledge status (Yip, 2004). By using these lower order questions, teachers are performing a 'checking routine' with the intention of determining whether or not the students can reproduce the answers they have in mind (Newton et al., 1999). Research has shown that the majority, fully $60 \%$, of the written questions on college tests in science are on this factual knowledge level (Lord \& Baviskar, 2007) and the same percentage is noted for verbally posed questions (Blosser, 2000).

Questions on levels above the factual knowledge level according to Bloom's taxonomy range from lower to higher levels of thinking. They are considered to demand higher order thinking skills of the students such as comprehension, application, analysis, synthesis, evaluation or conclusions. These questions are denoted as higher order questions by 
Yip (2004). An inclusion of higher order questions as a part of the classroom discourse may promote deeper and more reflective thinking.

To develop variety in teachers' questioning, it is necessary to know what type of questions they pose. In order to help teachers to focus on how they pose questions, Blosser (2000) has created a question classification system which is based on Bloom's Taxonomy. Her classification system is called the Question Category System for Science (QCSS) where questions are classified as being of one of four major types; Managerial, Rhetorical, Closed Questions or Open Questions. We have used QCSS in order to identify the different types of questions posed. Managerial questions are not within the scope of this study since we are focusing extensively on science questions. The rhetorical questions posed in the material are mainly answered by the teachers themselves and, together with managerial questions, will not be discussed further.

In order to answer the closed questions, it is mainly the lowest level of thinking skills at the lowest level in Bloom's taxonomy that are required. They are therefore considered to belong to lower order questions. Since the lowest level is mainly about factual information, closed questions generally have a limited number of correct answers which only need a one- or two-word answer (Blosser, 2000; Chin, 2004). It is also assumed that students have been exposed to the information needed in order to solve a closed question (Blosser, 2000; Chin, 2004). Some examples of questions with a limited number of answers are 'Which contributes more to an atom's mass; electrons or protons?', 'What is meant by an insulator?' and 'What are plant cell walls made of?'

A wider range of acceptable answers are anticipated to open questions, and they are said to require thinking from one or more of the five levels above the lowest level in Blooms taxonomy. These types of questions draw on students' past experience and often cause students to give their own opinions, and also to justify these opinions. Other characteristics of open questions are that they often cause students to infer or identify implications, to formulate hypotheses and to make judgements based on their own values or standards.

Blosser (2000) has also suggested that both closed and open questions could be further divided into the types of thinking expected, Question Function, according to Table 1.

However, within a sociocultural view, we cannot claim to know what kind of thinking operations take place in the human brain. Or, as Lemke (2001) more elegantly puts it ' ... what matters to learning and doing science is primarily the socially learned cultural traditions of what kinds of discourses and representations are useful and how to use them, far more than whatever brain mechanism may be active while we are doing so' (p. 298). What we can observe are the questions and responses actually posed and responded to in the ongoing interpersonal communication, and visual communication that includes gestures and interaction with equipment such as drawings, pictures and other artefacts as 3D models for example. The questions and responses studied here are

Table 1. Question type and question function.

\begin{tabular}{ll}
\hline Question type & \multicolumn{1}{c}{ Question function } \\
\hline Closed Questions & $\begin{array}{l}\text { Cognitive-memory operations } \\
\text { Convergent thinking operations } \\
\text { Open Questions }\end{array}$ \\
& $\begin{array}{l}\text { Divergent thinking operations } \\
\text { Evaluative thinking operations }\end{array}$ \\
\hline
\end{tabular}

Sources: Blosser (2000). Adapted from Blosser (1973, p. 10). 
seen as possible signs of different ongoing thinking operations. Although we cannot make any claim to explain what students think, we believe that Blossers' way of classifying questions is sufficient for this study. For simplicity in the following text, the question will be referred to as Closed Memory Questions, Closed Convergent Questions, Open Divergent Questions and Open Evaluative Questions.

There are many similarities between the two levels of closed questions. Both Blosser (2000) and Chin (2004) have described that Closed Memory Questions and Closed Convergent Questions have a limited number of acceptable responses and that they both mainly focus on factual recall. They are often of the type where students are expected to fill in the blanks orally or respond with one- or two-word answers (Blosser, 2000). Both Closed Memory Questions and Closed Convergent Questions are considered to belong to the lower order of questions. But Closed Convergent Questions may not always be of the type that requires lower order thinking, despite a limited number of possible answers. These questions can also be designed to cause students to pick out similarities and differences (Blosser, 2000), to ask students to compare and contrast, apply previously learnt facts to a new problem, or to make a judgement about two different statements which 'need not always be pitched at lower levels of thinking' (Chin, 2004, p. 16).

Open Divergent Questions promote discussion as do Open Evaluative Questions, and they both encourage students to hypothesise, speculate, invent possibilities, interpret and share ideas (Chin, 2004). One example of a Divergent Thinking Question is 'What would the atmosphere on earth be like with a weaker gravity?' and a corresponding example of an Open Evaluative Question is 'What do you think is the best way to depict the results of this experiment'?

As pointed out in the introduction, this paper examines the extent to which boys or girls participate in joint science-classroom communication, and furthermore any possible differences in the quality of the questions posed by male and female teachers. Here, quality is defined according to the four categories used in QCSS. A closer description of the rationale behind the coding of the questions is provided in the method section.

\section{Gender equality in Swedish school}

Sweden and the other Nordic countries are considered to be at the top with respect to overall gender equality and gender equality in education (World Economic Forum, 2015). High equality for Sweden and the Nordic countries with respect to inter school variations due to socio-economic factors is also reported in PISA (OECD, 2014). One of several fundamental requirements in The Swedish Curriculum for the compulsory school is to represent and impart equality between women and men, and ensure that no one is subjected to discrimination on the grounds of gender, or for any other reason:

The school should actively and consciously further equal rights and opportunities for women and men. The way in which girls and boys are treated and assessed in school, and the demands and expectations that are placed on them, contributes to their perception of gender differences. The school has a responsibility to counteract traditional gender patterns. It should thus provide scope for pupils to explore and develop their ability and their interests independently of gender affiliation. (National Agency for Swedish Education, 2011 p. 10) 
Everyone involved in school is obliged to follow these fundamental values. However, gender equality is more of a political goal and a norm in the Swedish society (Nyström, 2009) and the curriculum does not include specific wording on how this should be accomplished in school, or on how teaching should be performed. This gives teachers a high degree of freedom in the organisation of their work. And despite high equality, there are some reported differences. A research summary has shown that older gender patterns persist; girls have higher final grades at the end of compulsory school and boys drop out of secondary school more often. The choice of higher education is also very gender-stereotyped (Nyström, 2009).

\section{Boys' greater share of space for interaction}

There are factors related to the questions posed by teachers that may give more classroom space for some students. For example, Tobin and Gallagher (1987) have described classroom norms allowing students to shout out answers without raising hands and some students they call 'Target students'. These students, often three to seven in each class, are very active in responding to teachers' questions without raising their hands, asking questions or giving comments on the lecture, or on other to students. Students who actively participate in the classroom interaction in this way are often considered by their teachers to be more skilled compared to more quiet students. Questions are often directed by teachers to these target students in order to move on, and to keep pace of the teaching. Lower cognitive questions tend to be posed almost at random, while higher cognitive questions tend to be directed towards target students. In grades 8-10, target students tended to be boys, irrespective of whether the class was taught by a male or female teacher (Tobin and Gallagher 1987). Other research, pointing in the same direction, shows that both male and female teachers spend more time interacting with boys than with girls (Hultman, 1990; Tobin, 1988; Wernersson, 2006). Findings on differences in male and female teacher-student interaction in college classes show that male teachers more often direct their questions to male students and that female teachers are equally likely to pose questions to both male and female students (Karp \& Yoles, 1976). Male teachers tend to pose twice as many questions as female teachers (Jones \& Wheatly, 1990). A study of video-recorded science-classroom activities at the end of Swedish lower secondary school confirms that both male and female teachers interact more with boys than with girls (Eliasson et al., 2016). Compared to girls, boys are also more likely to initiate teacher interactions, to volunteer to answer questions and to call out answers (Kahle \& Meece, 1994; Jones \& Wheatly, 1990). They are also more likely to interrupt peers or teachers in order to make room for their own talk (Hultman, 1990). Research has shown that girls' willingness to interact increases in smaller groups (Einarsson, 2003) and that girls are less willing to interact in groups where they are in a minority. But even in groups where girls are in a majority, it is shown that boys receive more attention (Wernersson, 2006). Teachers often accept boys violating the classroom rules without protest or with only lame protests (Wernersson, 2006). Teachers also tend to value boys' experiences more than girls' and they generally treat boys more favourably (Murphy \& Whitelegg, 2006; Staberg, 1994; Wernersson, 2006). Hultman (1990) has argued that girls in several ways take a second place in school compared to boys and that one consequence is that girls are socialised into silence in public. 


\section{The aim of the study}

This study explores to what extent teachers pose different types of science question, and if the type of question posed is a factor influencing the extent to which boys or girls respond to them, since this may lead to boys and girls having different opportunities to participate in and to achieve higher levels of understanding. Another aim is to explore if there are any differences in the type of questions posed by male or female teachers, and if boys or girls respond to a different extent to questions posed by male or female teachers. In this study, the following two research questions have been formulated:

- To what extent do male and female science teachers pose different types of questions?

- Does the type of science question posed influence the extent to which boys or girls respond to them?

\section{Method}

\section{The empirical material}

This empirical material originates from the SONAT project ${ }^{1}$ and is part of a larger body of video recordings from science-classroom practices at the end of lower secondary school (Grade 9). The collection of data together with a more detailed description of the database and the SONAT project can be found in a previously published article (Eliasson et al., 2016). Aspects that are relevant for the present study will be described here.

The video documentation was conducted at the end of the autumn of 2013 and the spring of 2014. The material from the science lessons studied consisted of several videos from each lesson, where up to three different cameras were arranged in different positions. All situations where some kind of teacher-led, whole-class instruction was filmed were marked as events in a software tool.

In order to define the events of teacher-student interaction in the material, the concepts Bids to Start and Closing were used. These concepts are described by Lemke (1990) as a teacher's first initiative to start a lesson as a shared social activity and to mark the ending of a lesson. The start of each event began when the teacher made the first attempt to create a common focus of attention, and ended when the shared communication was transformed into other classroom activities. The length of each filmed event from a Bid to start to a Closing ranged from 2.5 seconds up to 50 minutes, and one lesson might include more than one event of varied length and content.

\section{The participants}

Within the framework of the SONAT project, one of several stated goals has been to conduct research on differences in science education between low- and high-performing schools. The differences between low- and high-performing schools are not a scope for this study, but the rationale behind the selection of them explains to some extent the variation of participants. Principals at potential schools were contacted by the researchers in order to find science teachers who were willing to participate in the research. The selection of participating schools was a convenience sample since it 
was the researchers who chose which schools to contact and these were to a varying degree known by the researchers in advance. The schools contacted were also geographically located in reasonable proximity to each researcher. The science teachers who agreed to participate, together with some of their students, were from six different schools in Sweden. Seven male teachers and seven female teachers were filmed during different science lessons held for 85 boys and 110 girls. The distribution of boys and girls in different lessons has varied. Sometimes, girls have been in the majority, and sometimes in the minority. In some lessons, the distribution of boys and girls has been equal.

The selected schools, one private and five public schools, were located in the southern and central part of Sweden and they differed in the size of municipality, the size of the school and in school performance. The variation in school performance was measured as average increment credit $^{2}$ and ranged between about 160 and 240 points. In two schools, the vast majority of students had a first language other than Swedish, three schools had a majority of students with Swedish as their first language, while one school exclusively had students with Swedish as their first language. Parents' average educational level ranged between 1.65 and 2.52, compared to the Swedish average of $2.25 .^{3}$

\section{Ethical concerns}

The SONAT project has addressed ethical considerations and the permissions required to film students in class. Any member of this research group undertakes to comply with these established conditions. Teachers and students have given their consent to participating in the study, and consent forms signed by their parents have been collected for under-aged students (younger than 15). Students who did not want to be filmed participated in the lessons outside the range of the camera.

In order to prevent an identification of the participants, no further details of the socioeconomic parameters will be given. Schools and participants have also been given fictitious names in order to protect the contributors' identities.

\section{Data analysis}

Altogether, 14 hours of ongoing events were studied further in order to identify and classify the scientific questions posed. The analytical software tool used was ATLAS.ti which is a workbench for qualitative analysis of large textual, graphical and audio-video data (Friese, 2013). This software was sufficient to sort, identify, display, repeat, select, transcribe and assign codes to different types of questions. Being able to view and review video-recorded situations was one advantage that influenced the validity of coding in a positive manner (Tiberghien \& Sensevy, 2012).

Since there is an uneven number of participant boys and girls, these calculations are normalised to reflect the assumption of an equal number of boys and girls in the material. Since the number of participant male and female teachers is equal, as is the proportion of communication measured in time, the number of questions posed by the teachers is not normalised. 


\section{How the material has been coded and quantified}

One of the aims of this study was to find out to what extent male and female teachers pose different types of questions, in this case measured as the number of closed or open science questions posed. Another aim was to find out to what extent boys or girls answer these different questions. In each video sequence where ongoing general communication occurs, all science questions posed by teachers have been identified. Each type of question posed is given a code containing information about question type, the sex of the teacher who is posing the question and the sex of the student who is responding to the question. Sometimes, several students have responded to the same question which means that the number of responses in the material is larger than the number of questions posed. We have not considered whether the response is right or wrong, or somewhere in between right or wrong. Any answer, whatsoever, to a question about science, has been considered sufficient to be included since, in this study, we believe that all the answers are serious attempts by the students to give a correct response. For example, from a total of 953 questions, boys have given the answer 'I do not know' to only 14 questions while girls have given the same answer 12 times.

Some of the properties of the open or closed questions described by Blosser (2000) are used to classify and to give the questions in the material a code. According to Blosser (2000), identifying keywords may sometimes (but not always) be a fruitful way to identify the type of question posed. For Closed Questions, she suggests the keywords who, what, when, where, name, how and why and for Open Questions words like discuss, interpret, explain, evaluate, compare, if or what if. The coding is done in two steps and the basis for the classification are video sequences and the transcripts of these.

Step 1: The first step in the classification is to determine whether the question posed is open or closed.

The question is considered to be a Closed Question if there are a limited number of acceptable responses, if students need to recall facts and if they have previously been exposed to the information requested (Code C).

The question is considered to be an open question if it anticipates a wide range of acceptable responses, the answers may be divergent, it draws on students past experiences, if it causes students to give and justify their opinions or lets students infer or identify implications, or if the student is urged to formulate a hypothesis (Code O).

Step 2: The closed questions posed are further divided into: (a) Closed Memory Questions (Code Cm) or Closed Convergent Questions (Code Cc) and likewise the open questions are further divided into Open Divergent Questions (Code Od) or Open Evaluative Questions (Code Oe) mainly according to the QCSS (Blosser, 2000).

\section{2a: Closed Questions}

If the question has been deemed to be closed, the next step is to consider if it belongs to Closed Memory Questions or to Closed Convergent Questions. This is done by determining if the questions could be answered by a one- or two-word answer, or if more words are needed or would be acceptable in the answer. 
If one- or two-word answers are sufficient or it is clear that factual knowledge is required, the question is deemed to be a Closed Memory Question (Code Cm). Examples of Closed Memory Questions (Code Cc) are:

- Will the light turn on if we close the switch?

- What kind of atom is composed of a proton and an electron?

- How much is 10 times 10 ?

- What is another word for formic acid?

\section{Closed Convergent Questions}

If more words are needed to build up the answer, if the student is asked to classify or pick out similarities and if the different words used are convergent in the way that they aim towards one single answer, the question is deemed to be a Closed Convergent Question (Code Cc). Examples of Closed Convergent Questions are:

- What parts comprise an atom?

- Which of these animals are mammals?

- Which characteristics are typical of a metal?

- What is the wording of Newton's first law?

The first example 'What parts comprise an atom' is a bit of a borderline example and seems not to differ with more than one word from a Closed Memory Question since we normally expect the answer 'electrons, neutrons and protons'. But since the physics lessons in grade nine often include atom and nuclear physics, other answers are possible, for example 'quarks', 'mostly emptiness', 'a nucleus and an electron cloud'. Therefore, we have coded the question as a Closed Divergent Question.

\section{2b: Open Questions}

Open questions are divided into two levels: Open Divergent Questions (Code Od) that may be answered with many divergent answers, but which do not require any form of evaluative judgements and Open evaluative Questions (Code Oe) that in some sense also ask for students' evaluation, opinion or students' own conclusions based on their own values and standards. Examples of Open Divergent Questions are:

- Which different applications for convex mirrors are you familiar with?

- What might life on Earth be like with different proportions of gases in the atmosphere?

- What should be included in a lab report?

Examples of Open Evaluative Questions are:

- What do you think is the reason for ...?

- What conclusions have you drawn from the results?

- Which one would you chose (and why)?

- What do you think are the benefits of ...? 
Table 2. Number of different types of questions posed by male and female teachers.

\begin{tabular}{lccrr}
\hline Question type & Male teacher $(N)$ & Female teacher $(N)$ & M-F & $p^{\text {a }}$ \\
\hline All Closed Questions & 391 & 439 & -48 & .096 \\
Closed Memory Questions & 266 & 315 & -49 & .042 \\
Closed Convergent Questions & 125 & 124 & 1 & .949 \\
All Open Questions & 31 & 92 & -61 & .000 \\
Open Divergent Questions & 31 & 80 & -49 & .000 \\
Open Evaluative Questions & 0 & 12 & -12 & - \\
\hline
\end{tabular}

${ }^{a} X^{2}$ tests on group differences are used to calculate $p$-values.

${ }^{b}$ No Open Evaluative Questions are asked by male teachers.

Once the type of question is identified and coded, each student response is given the same code with an additional $B$ or $G$ for boy or girl.

\section{Results}

The video-recorded material includes a total of 953 questions posed by teachers (Table 2). Eighty-seven per cent of the questions posed by all teachers are closed questions, and $13 \%$ are open questions. Female teachers pose more questions $(n=531)$ than male teachers $(n$ $=422$ ) and the most common type of questions in the material is Closed Memory Questions. Regardless of type, there are few open questions in the material. Because of the small number of open questions, there is reason to be cautious when drawing conclusions about any possible differences.

Excerpt 1 is a typical sequence of communication that illustrates how the teacher mainly poses closed questions of the type Closed Memory Questions $(\mathrm{Cm})$, even though the first closed question posed (in line 01) is of the type Closed Convergent Question $(C c)$. In this sequence, the teacher is drawing a model of an atom on the whiteboard while simultaneously posing seven questions to students. Six of the seven questions posed are answered by boys $(B)$. Four of these questions are answered by students after having been invited to speak by the teacher. Three questions are answered by boys spontaneously calling out their responses without any raising of hands. One- or two-word answers are given to all questions in Excerpt 1, this being a typical feature of the responses to both Closed Memory Questions and Closed Convergent Question in the material. Memory recall alone is considered adequate to answer these questions.

\section{Excerpt 1:}

$01 \mathrm{~T}$ : Yes, what do you know about an atom? If we consider the different parts of the atom? $(C c)$

$02 \mathrm{~B}: \quad$ Nucleus. $(B C c)$

$03 \mathrm{~T}$ : What are the different parts of an atom? I heard nucleus. (No code, repeating $Q$ in line 01)

$04 \mathrm{~T}$ : Ok. What can be found in a nucleus? $(\mathrm{Cm})$

$05 \mathrm{~B}: \quad$ Protons and neutrons $(\mathrm{BCm})$

06 T: Two different particles in the nucleus. Proton and neutron.

$07 \mathrm{~T}: \quad$ Emm. Was that the entire atom? Is there anything missing? Julie? $(\mathrm{Cm})$

$08 \mathrm{G}$ : Electrons. (GCm)

$09 \mathrm{~T}$ : $\quad$ Electrons and where are they? $(\mathrm{Cm})$

$10 \mathrm{~B}$ : Outside. $(\mathrm{BCm})$

$11 \mathrm{~T}$ : Outside ... And we usually draw it like this. 
$12 \mathrm{~T}$ : Ehum. I wrote plus there ... why? $(\mathrm{Cm})$

$13 \mathrm{~B}: \quad$ It is plus charged. $(B C m)$

$14 \mathrm{~T}$ : It is plus charged. Exactly.

$15 \mathrm{~T}$ : And what about the neutron? $(\mathrm{Cm})$

16 B: Neutral. $(B C m)$

$17 \mathrm{~T}$ : Neutral, thus no charge at all.

$18 \mathrm{~T}$ : What's the charge of the electron? $(\mathrm{Cm})$

$19 \mathrm{~B}:$ Minus $(\mathrm{BCm})$

$20 \mathrm{~T}$ : Minus ... yes.

Thirteen per cent of All Open Questions posed in the material correspond to a total number of 123 questions. As previously described by Blosser (2000), the open questions anticipate a wide range of acceptable responses, they draw on students' past experiences and may cause students to give and justify their opinions. However, longer and more extensive student responses are rare in the material. Excerpt 2 shows what kind of answer students give to questions that have been classified as open questions.

\section{Excerpt 2:}

$01 \mathrm{~T}$ : What should we consider when making lab instructions? $(\mathrm{Od})$

$02 \mathrm{G}$ : If someone else could follow it. (GOd)

$03 \mathrm{~T}$ : $\mathrm{Mm}$... someone else should be able to follow it without asking you. We should be meticulous and very clear.

$04 \mathrm{~T}$ : And what else should we consider? If we hand the instructions over to someone else? There may

be some danger, right? What should we consider when writing the instruction then? $(\mathrm{Od})$

$05 \mathrm{G}: \quad$ Write what risks there are. $(G O d)$

$07 \mathrm{~T}$ : Yes, write what risks there are.

The teacher in Excerpt 2 poses two open questions of the type Open Divergent Questions $(O d)$. Here, the answers given to the open questions are not as advanced as suggested by Blosser (2000). However, there is a wide range of possible answers to the question posed in line 01 . The second question is a bit more focused by the teacher, and therefore is not as open as the first question. The question is still considered an open question since there are several possible answers such as: 'how to avoid risks', 'list different kinds of risks of injury' or 'the risk of making sloppy measurements'.

In Excerpt 3, the students have just finished a lab session where small groups have rotated between different stations about different forms of energy transformation. The way the teacher poses the questions indicates wanting to make the students aware of what the different labs have in common. First, an open question is posed in line 01 . The question requires some evaluation $(\mathrm{Oe})$ of what all the different labs have in common. In line 06 , the teacher focuses the question somewhat by posing a new question to help the students find the common features of all the labs. However, since the basic question still remains, this question is also coded as an open question. 


\section{Excerpt 3:}

$01 \mathrm{~T}$ : Now I would like to ask you one thing. What have you ... what conclusions have you drawn about the labs? For all lab stations? (Oe)

$02 \mathrm{~B}: \quad$ Anja. I have not drawn any conclusions. I just wrote. $(B O e)$

$03 \mathrm{~T}$ : But what do they all have in common? (Clarification of the question posed in line 01, no code)

$04 \mathrm{G}$ : Most of them are about kinetic energy and potential energy. (GOe)

$05 \mathrm{G}: \quad$ And about heat as well. (GOe)

$06 \mathrm{~T}$ : But what happens to the energy? $(\mathrm{Oe})$

$07 \mathrm{G}: \quad$ It is transformed. (GOe)

$08 \mathrm{~T}$ : Transformed, Ok. Energy is converted. (Confirmation)

There are few Open Evaluative Questions in the material. From a total of 953 questions, only 12 are of this type, and none of them is posed by a male teacher as is shown in Tables 2 and 4 .

In this material, boys respond to more closed questions than girls, something that is true for All Closed Questions as well as for Closed Memory Questions and for Closed Convergent Questions (Table 3). The number of responses to open questions are few. There are no significant differences between the numbers of answers from boys or girls to this type of questions.

Tables 4 and 5 show the number of student responses that are given to the different questions posed by male and female teachers, respectively. Table 4 shows that nearly twice as many of the answers to All Closed Questions posed by male teachers are from boys. In terms of percentage, about $66 \%$ of the answers to Closed Memory Questions posed by male teachers were from boys compared to $34 \%$ from girls. For the Closed Convergent Questions, the corresponding proportions are $60 \%$ and $40 \%$, respectively.

Table 3. Normalised number of responses for boys and girls to open and closed questions.

\begin{tabular}{lccrl}
\hline Question type & Boy $(N)$ & Girl $(N)$ & B-G & $p^{\text {a }}$ \\
\hline All Closed Questions & 606 & 415 & 191 & .000 \\
Closed Memory Questions & 412 & 270 & 142 & .000 \\
Closed Convergent Questions & 194 & 145 & 49 & .008 \\
All Open Questions & 72 & 74 & -2 & .876 \\
Open Divergent Questions & 67 & 65 & 2 & .902 \\
Open Evaluative Questions & 5 & 9 & -4 & .390 \\
\hline
\end{tabular}

${ }^{a} X^{2}$ tests on group differences are used to calculate $p$-values.

Table 4. Normalised number of responses for boys and girls to open and closed question posed by male teachers.

\begin{tabular}{lccrc}
\hline Question type & Boy $(N)$ & Girl $(N)$ & B-G & $p^{\text {a }}$ \\
\hline All Closed Questions & 295 & 168 & 127 & .000 \\
Closed Memory Questions & 201 & 105 & 96 & .000 \\
Closed Convergent Questions & 94 & 63 & 31 & .013 \\
All Open Questions & 18 & 13 & 5 & .369 \\
Open Divergent Questions & 18 & 13 & 5 & .369 \\
Open Evaluative Questions & 0 & 0 & 0 & - \\
\hline
\end{tabular}

${ }^{a} X^{2}$ tests on group differences are used to calculate $p$-values.

${ }^{b}$ No Open Evaluative Questions are asked by male teachers. 
Table 5. Normalised number of responses for boys and girls to open and closed question posed by female teachers.

\begin{tabular}{lcccc}
\hline Question type & Boy $(N)$ & Girl $(N)$ & B-G & $p^{\text {a }}$ \\
\hline All Closed Questions & 308 & 246 & 62 & .008 \\
Closed Memory Questions & 209 & 164 & 45 & .019 \\
Closed Convergent Questions & 99 & 82 & 17 & .212 \\
All Open Questions & 55 & 60 & -5 & .597 \\
Open Divergent Questions & 49 & 51 & -2 & .765 \\
Open Evaluative Questions & 6 & 9 & -3 & .483 \\
\hline a $X^{2}$ tests on group differences are used to calculate $p$-values. & & &
\end{tabular}

The difference in the number of responses from boys or girls to All Closed Questions posed by female teachers is slightly lower than to All Closed Questions posed by male teachers (Table 5). Fifty-six per cent of the answers to Closed Memory Questions posed by female teachers come from boys, and 44\% from girls. For Closed Convergent Questions, the corresponding proportions are $55 \%$ and $45 \%$, respectively.

There are no obvious differences in the number of answers from boys or girls to All Open Questions and Open Divergent Questions, regardless of if the questions are posed by male or female teachers. No male teacher poses an Open Evaluative Question, and there are no differences between boys and girls regarding Open Evaluative Questions posed by female teachers.

\section{Discussion and conclusions}

The results in this study clearly show that the majority of the questions posed are closed science questions. Eighty-seven per cent of all questions are closed questions, this share being somewhat higher compared to previously reported figures (Blosser, 2000; Lord \& Baviskar, 2007). Closed questions have mainly been described as lower order questions even though there are some exceptions (Blosser, 2000; Chin, 2004; Yip, 2004). There are also descriptions of how teachers often use closed questions in order to evaluate what students have learnt (Yip, 2004), and that their use is thought to be to promote factual knowledge recall (Chin, 2004). On the other hand, it is widely believed that the use of higher order questions (Yip, 2004), characterised here as open questions, promotes deeper and more reflective thinking in students. However, there are few open questions in the present study and the few answers given by participating students are not as extensive as those described in the literature (Blosser, 2000; Lord \& Baviskar, 2007). One conclusion is that students in the setting studied are not to any higher extent given the opportunity to practise the use of the scientific language, a practice that the science education community agrees leads to better learning and understanding.

Compared to girls, boys respond to a greater share of the Closed Memory Question (60\%) and Closed Convergent Question (57\%). These results give us a more detailed picture of the content of the boys' greater share of the classroom communication. And perhaps the high degree to which boys answer closed questions is not so surprising since previous research has reported that boys' share of the general space for classroom communication is greater than that of girls (Hultman, 1990; Jones \& Wheatly, 1990; Karp \& Yoles, 1976; Kahle \& Meece, 1994; Wernersson, 2006). These results have been re-proven in more recent research and holds true regardless of the proportion of boys 
and girls in the classes studied (Eliasson et al., 2016). In order to explain this discrepancy between the number of responses from boys and girls to closed questions, it may be fruitful to consider the characteristics of the posed questions and the general image of boys in the science classroom. Two of the most striking features of the closed questions are that there are few possible correct answers to these questions, and that they can often be responded to with only one or two words, something which has also been described by Blosser (2000) and Chin (2004). A reasonable explanation for boys' greater proportion of responses is that the use of closed questions favours boys since it is obviously easier to shout out a short answer. Previous research has also shown that boys call out their answers more often than girls (Jones \& Wheatly, 1990; Kahle \& Meece, 1994). So, the characteristics of the closed questions, such as demanding short factual responses, appear to influence the extent to which boys respond to them. One implication may be that by using a high proportion of closed questions, teachers give boys greater access to the commonly shared interaction space. However, this is not necessarily an advantage for the boys, since they get less opportunities to practise their ability to talk science and to practise higher order thinking by answering higher order questions. An important finding is therefore that the nature of questions posed with respect to their cognitive level, measured here as closed or open questions, is a significant factor that skews class participation. Closed questions seem to encourage male domination by allowing the calling out of answers without being invited. Another finding is that open questions, which place higher cognitive demands on students by eliciting higher order thinking and argumentation from all students, also seem to invite wider participation from girls. In the setting in which the present study was conducted, these open questions elicited an equal number of responses from boys and girls. The same pattern is also true for Closed Convergent Questions to which the girls' proportion of responses is higher as compared to Closed Memory Questions.

Even if previous research has shown that both male and female teachers tend to interact more with boys than with girls (Wernersson, 2006), we cannot draw any such conclusions from this material. One important reason for this is that the present study does not distinguish between responses from students who are invited to speak and those responses that are called out without the teacher's permission. So, when a student of any gender calls out the answer without having been invited to speak, we cannot say that this reflects teacher-student interaction. In Excerpt 1, we showed examples of how boys called out their answers, and a typical situation was described when this applied to three questions out of seven. Even if teachers in one way or another (seem to) accept students calling out their answers, we cannot say that this behaviour is the same as teachers choosing to interact with their students. It would be more correct to say that it is the student who chooses to take part in the discussion.

For open questions, no differences exist for boys and girls, regardless of if the questions are posed by male or female teachers. This differs from what has previously been reported by Tobin and Gallagher (1987) who showed that teachers direct higher order questions to target students who often tend to be boys. However, boys respond to nearly twice as many closed questions posed by male teachers as compared to girls. Their share of responses to Closed Memory Questions posed by male teachers is 66\% while the corresponding share of boys' responses to female teachers posing these questions is lower, $56 \%$. However, this is still above the girls' share. For Closed Convergent Questions, there is no significant 
difference in the answering frequency between boys and girls in classrooms with female teachers. The type of questions posed and who answers them seem to be significant. Of all the questions posed in lessons held by male teachers, $92 \%$ are closed questions and in lessons held by female teachers, this share is $82 \%$. This difference of 10 percentage points might be one explanation why boys respond to questions posed by male teachers to a higher extent than girls.

One implication of too narrow a focus on closed questions is that this may be in conflict with the Swedish syllabi which clearly state that teaching should give all students the opportunity to use and develop knowledge and tools for expressing their own arguments, and to examine the arguments of others.

The fact that boys still take up more space in classroom interaction may also affect girls' attitudes towards science, and ultimately whether they aim for a future science career. One explanation is that indications, presented by Moeller Andersen and Lund Nielsen (2003), show that interaction and communication between teachers and students has a general effect on students' motivation and engagement in science education. Our results show that the number of closed questions posed affects the degree to which boys or girls interact with teachers, which potentially could affect motivation. Osborne et al. (2003) have described how gender and the quality of teaching are two of the most important factors influencing attitudes towards science. It may be that girls still play a less prominent role in the science classroom of today despite their academic success, and the results presented here suggest that a high proportion of posed open questions in science education is perhaps part of the explanation.

Finally, to facilitate higher cognitive levels by reminding teachers to pay attention to the effect that different types of questions have on students' learning, and to make them aware of their use of different question types are constantly repeated advices. For example, Chin (2007) suggests that teachers could record teaching sessions, analyse the various interactions involving teacher questioning and follow-up questions, and reflect on alternative modes of interaction. Another more easily implemented suggestion from Smart and Marshall (2013) to start with would be to plan and prepare questions in advance of instruction.

In summary, lower cognitive questions are the most asked type of questions posed by both male and female teachers in the classrooms studied. About $13 \%$ of the questions posed are open questions which are considered as higher cognitive question. The nature of questions asked seems to skew class participation and one result is a higher frequency of answers from boys to lower order questions. The difference in boys' and girls' response rate is even greater if the close questions are asked by male teachers.

\section{Limitations of study}

Data used in this study were derived from events with general teacher-student interaction in whole-class setting. The results presented can only address the science questions posed during these events and are not applicable to other classroom activities. The analysis of data was based on the number of posed questions and responses of individuals who participated in the interaction, but it is collectively expanded to the different groups of teachers and students as a whole. There is no suggestion that the results presented can apply generally to all settings. Since the study was based on a sample of six schools, we have to exercise a degree of caution in generalising from the data. However, as argued 
in the introduction, together with previous and future research, our findings will help us to broaden our knowledge about gendered inequalities in the science classroom.

\section{Notes}

1. SONAT is a Swedish-Danish research project with members from Malmö University, Linnæus University, Aarhus University, Mälardalen University, and Mid Sweden University, with focus on relations between trends in large-scale studies and how teaching and learning are constituted in the science classroom.

2. Average increment credit for Swedish schools is 215, and maximum credit is 320 (2014). http://siris.skolverket.se/siris/f?p=101:54:0::NO.

3. Three levels of parents' educational are used: passed primary or lower secondary education, passed upper secondary school and tertiary education. http://siris.skolverket.se/siris/f?p= SIRIS:164:0::NO.

\section{Disclosure statement}

No potential conflict of interest was reported by the authors.

\section{Funding}

This study is conducted within the framework of SONAT, 'The relation between trends in largescale studies and how teaching and learning are constituted in the science classroom', which is financially supported by the Marcus and Amalia Wallenberg Foundation [grant number MAW 2012.0094].

\section{References}

Bloom, B. S. (1956). Bloom's taxonomy of educational objectives, handbook 1: Cognitive domain. New York, NY: David McKay Company.

Blosser, P. E. (2000). How to ask the right questions. Arlington: NSTA Press.

Chapin, S. H., \& Anderson, N. C. (2003). Crossing the bridge to formal proportional reasoning. Mathematics Teaching in the Middle School, 8(8), 4-20.

Chin, C. (2004). Questioning students in ways that encourage thinking. Teaching Science, 50(4), $16-$ 21.

Chin, C. (2006). Classroom interaction in science: Teacher questioning and feedback to students' responses. International Journal of Science Education, 28(11), 1315-1346.

Chin, C. (2007). Teacher questioning in science classrooms: Approaches that stimulate productive thinking. Journal of Research in Science Teaching, 44(6), 815-843.

Driver, R., Asoko, H., Leach, J., Mortimer, E., \& Scott, P. (1994). Constructing scientific knowledge in the classroom. Educational Researcher, 23, 5-12.

Driver, R., Newton, P., \& Osborne, P. (2000). Establishing the norms of scientific argumentation in classrooms. Science Education, 84(3), 287-312.

Duschl, R., \& Osborne, J. (2002). Supporting and promoting argumentation discourse in science education. Studies in Science Education, 38(1), 39-72.

Einarsson, C. (2003). Lärares och elevers interaktion i klassrummet. Betydelsen av kön, ålder, ämne och klasstorlek samt lärares uppfattningar om interaktionen [Teachers and students interaction in the classroom. The importance of gender, age, subject and class size and teachers' perceptions of the interaction]. Linköping: Filosofiska fakulteten, Linköpings universitet.

Eliasson, N., Karlsson, K. G., \& Sørensen, H. (2016). Teacher-student interaction in contemporary science classrooms: Is participation still a question of gender? International Journal of Science Education, 38(10), 1655-1672, doi:10.1080/09500693.2016.1213457 
Friese, S. (2013). ATLAS.ti 7 user guide and reference. Berlin: Atlas.ti Scientific Software Development GmbH.

Hultman, T. G. (1990). Språk och kön i skolan [Language and sex in school]. Tidskrift för genusvetenskap, 1, 19-29.

Jensen, J. L., McDaniel, M. A., Woodard, S. M., \& Kummer, T. A. (2014). Teaching to the test ... or testing to teach: Exams requiring higher order thinking skills encourage greater conceptual understanding. Educational Psychology Review, 26(2), 307-329. doi:10.1007/ s10648-013-9248-9

Jones, M. J., \& Wheatly, J. (1990). Gender differences in teacher-student interactions in science classrooms. Journal of Research in Science Teaching, 27(19), 861-874.

Jurik, V., Gröschner, A., \& Seidel, T. (2013). How student characteristics affect girls' and boys' verbal engagement in physics instruction. Learning and Instruction, 23, 33-42.

Kahle, J. B., \& Meece, J. (1994). Research on gender issues in the classroom. In D. L. Gable (Ed.), Handbook of research on science teaching and learning (pp. 542-557). New York, NY: Macmillan.

Karp, D., \& Yoles, W. C. (1976). The college classroom: Some observations on the meanings of student participations. Sociology and Social Research, 60(4), 421-439.

Kelly, A. (1988). Gender differences in teacher-pupil interactions: Meta-analytic review. Manchester: University of Manchester, Department of Sociology.

Lemke, J. L. (1990). Talking science: Language, learning and values. Norwood, NJ: Ablex.

Lemke, J. L. (2001). Articulating communities: Sociocultural perspectives on science education. Journal of Research in Science Teaching, 38(3), 296-316.

Lord, T., \& Baviskar, S. (2007). Moving students from information recitation to information understanding: Exploiting bloom's taxonomy in creating science questions. Journal of College Science Teaching, 26(5), 40-44.

Moeller Andersen, H., \& Lund Nielsen, B. (2013). Video-based analyses of motivation and interaction in science classrooms. International Journal of Science Education, 35(6), 906-928. doi:10.1080/09500693.2011.627954

Mortimer, E. F., \& Scott, P. H. (2003). Meaning making in secondary science classrooms. Great Britain: Ashford.

Murphy, P., \& Whitelegg, E. (2006). Girls in the physics classroom. A review of the research on the participation of girls in physics. London: Institute of Physics.

National Agency for Education. (2011). Curriculum for the compulsory school, preschool class and the recreation centre, 2011. ISBN:978-91-86529-58-1. Stockholm.

Newton, P., Driver, R., \& Osborne, J. (1999). The place of argumentation in the pedagogy of school science. International Journal of Science Education, 21(5), 553-576. doi:10.1080/ 095006999290570

Nyström, E. (2009). Nordisk forskning om genus och jämställdhet $i$ skola och utbildning: 2005-2009 [Nordic research on gender and equality in school and education] 20052009. Umeå: Umeå University

Organisation for Economic Co-operation and Development. (2014). PISA 2012 results: What students know and can do - student performance in mathematics, reading and science (Volume 1, Rev. edition, February). PISA, OECD Publishing. http://dx.doi.org/10.1787/ 978264208780-en

Osborne, J., Simon, S., \& Collins, S. (2003). Attitudes towards science: A review of the literature and its implications. International Journal of Science Education, 25(9), 1049-1079. doi:10.1080/ 0950069032000032199

Skolverket. (2009). Vad påverkar resultaten i svensk grundskola? Kunskapsöversikt om betydelsen av olika faktorer [What affects the results in Swedish primary school? A systematic review of the importance of different factors]. Stockholm: Fritzes.

Smart, J. B., \& Marshall, J. C. (2013). Interaction between classroom discourse, teacher questioning, and student cognitive engagement in middle school science. Journal of Science Teacher Education, 24, 249-267. doi:10.1007/S10972-012-9297-9

Staberg, E. M. (1994). Gender and science in Swedish compulsory school. Gender \& Education, 6(1), $35-46$. 
Tiberghien, A., \& Sensevy, G. (2012). The nature of video studies in science education. In D. Jorde \& J. Dillon (Eds.), Science education research and practice in Europe. Retrospective and prospective (pp. 141-179). Rotterdam: Sense.

Tobin, K. (1988). Differential engagement of males and females in high school science. International Journal of Science Education, 10(3), 239-252.

Tobin, K., \& Gallagher, J. J. (1987). The role of target students in the science classroom. Journal of Research in Science Teaching, 24, 61-75.

Wernersson, I. (2006). Genusperspektiv på pedagogik [A gender perspective on pedagogy]. Stockholm: Högskoleverket.

Wertsch, J. (1991). Voices on the mind: A socio-cultural approach to mediated action. Cambridge: Cambridge Press.

Wilen, W. W. (1991). What research says to the teacher: Question skills, for teachers (3rd ed.). Washington, DC: National Education Association.

World Economic forum. (2015). Global gender Gap report 2015. Geneva: World Economic Forum. Yip, D. Y. (2004). Question skills for conceptual change in science instruction. Journal of Biological Education, 38(2), 76-83. doi:10.1080/00219266.2004.9655905 